\title{
Conceptual Design and Flight Envelopes of a Light Aircraft for Mars Atmosphere
}

\author{
Marko Ž. EKMEDŽIĆ, Aleksandar BENGIN, Boško RAŠUO
}

\begin{abstract}
In this paper is presented a new conceptual design of the light aircraft for Mars atmosphere, ALPEMA. It allows atmospheric dropping (aeroshell), as well as direct take-off from Martian surface. Complex atmosphere demanded for simplified yet efficient wing geometry, capable of maximizing Lift-to-Drag ratio. Martian atmospheric pressure, density, temperature and speed of sound variations, demand a scrutinized powerplant choice. Efficient aspect ratio and drag polar lead to optimal flight envelopes as a proof of sustainability of ALPEMA project. Special performances and basic aerodynamics provide boundaries and constraints of the project, in line with similar approaches. Chosen propeller allows for ALPEMA to use maximum power capabilities of its engine, described through $V_{\min }$ and $V_{\max }$, which are significant inputs for flight envelope. Envelope provides effective width and profile for a variety of possible missions. ALPEMA's specific propeller and engine are a certain comparative advantage, together with its flight envelope.
\end{abstract}

Keywords: aerodynamics; atmosphere; flight; light aircraft; flight envelope; flight speed; Mars

\section{INTRODUCTION}

Efforts to overcome numerous challenges observable in Martian atmosphere are one of the ongoing and permanent topics for aerospace engineering in last decades. Engineering community, as well as state agencies or private entrepreneurs presented a variety of projects, especially in last decade. Special accent is on light aircraft, although there were also projects characterized with larger and heavier aircraft. Main challenges for the very design are encompassed by wing geometry and aircraft weight (or distribution of mass), which then in turn influence aircraft aerodynamics, but one has to also take into account powerplant specifics, as well as environmental factors. When specific mission bound all those invariables and variables, we can see the full spectrum of aircraft capabilities and possibilities. Most concurrent projects foresee missions such as collecting data or atmospheric samples, scanning and imaging of surface, topography or physical properties or some simpler or semi-complex tasks related to future Mars settlements. In that sense, ALPEMA (Atmospheric Light Prototype of Environmental Mars Aircraft) follows that trend. ALPEMA mission can be defined as the following: - 1) Aeroshell dropping, or takeoff from planetary surface; 2) Reaching operational height, or ceiling; 3) Activation of sensors and start of data collecting - atmospheric composition, pressure, temperature, density, winds nature and behavior, humidity and methane content; 4) Taking Hi-Res photos of Martian surface in standard and infrared mode; 5) collecting irradiation data and magnetospheric data; 6) Parachute or standard landing, depending on available surface topology. During the mission, certain constraints have to be taken into consideration, and before all, material strength, the duration of battery, usable ceiling and critical atmospheric conditions, i.e. winds and vortexes.

Numerous sources cite a large variety of approaches to Martian atmospheric flight problematics, offering full spectrum of solutions and analysis methods [1-5]. Special cases deal with dropping and inserting of aeroshell aircraft into Martian atmosphere, as one of nowadays most ergonomic methods of flight starting, which compensates greatly for most of limitations of Martian atmosphere [68]. With growing scientific and engineering knowledge related with flight in complex Martian conditions, analysis and synthetization of results will allow for more precise and effective projects, employing various and versatile tools [9-11].

Martian atmosphere shows specifics, which make it strictly different than the atmosphere of Earth. For decades, it is analysed in all available ways, from simple observation and scanning from Earth's orbit, all the way to collecting invaluable data via probes and various robotic rovers. In most cases, it is a scientific consensus to scale data between Earth and Mars, in order to compensate for variations in Martian atmosphere. In such a way, parameters necessary for analysis and calculation of flight to Mars are seen in scaling relation with their respective counterpart on Earth. More precisely, important parameters in Martian atmosphere are expressed as functions of same parameters on Earth.

When observing Martian atmosphere, certain parameters or values are of special interest. First of all, the average atmospheric pressure, which reaches some 600$636 \mathrm{~Pa}(0.087 \mathrm{psi})$ on planetary surface, which compared to Earth atmosphere of $101.325 \mathrm{kPa}$ (14.696 psi) on sea level, values to less than $1 \%$. Nevertheless, it is worth noting that pressure values along the height of Martian atmosphere vary greatly, from $0-72 \mathrm{~Pa}$ on the summit of Olympus Mons, to more than $1155 \mathrm{~Pa}$ deep into Hellas Planitia. Regarding pressure, it has to be noted that it often exceeds Armstrong limit for standard unprotected human body (Tab. 1).

Table 1 Pressure referent values
\begin{tabular}{|l|c|}
\hline \multicolumn{1}{|c|}{ Location } & Pressure (kPa) \\
\hline Olympus Mons (peak) & 0.03 \\
\hline Mars (average) & 0.60 \\
\hline Hellas Planitia (bottom) & 1.16 \\
\hline Armstrong limit & 6.25 \\
\hline Mont Everest (peak) & 33.70 \\
\hline Earth (sea level) & 101.33 \\
\hline Dead Sea (surface) & 106.70 \\
\hline
\end{tabular}

Strong differences in atmospheric properties between Earth and Mars are obvious when atmospheric weight is compared as well. Martian atmosphere with its 25 teratonnes is some 206 times lighter than Earth's atmosphere (5148 teratonnes). Equally striking are the 
scaling heights on Earth and mars, which are compared as 11 and 7 kilometres, respectively.

Another boundary and limitation is the chemical composition of Martian atmosphere (Fig. 1). Its mean molar mass is $43.34 \mathrm{~g} / \mathrm{mol}$. The constituents are carbondioxide (95.32-95.9\%), argon (1.6-2\%), nitrogen (1.9$2.7 \%)$, oxygen $(0.13-0.14 \%)$, carbon-monoxide (0.06$0.08 \%$ ), with traces of water (around $0.021 \%$ ), nitric-oxide (less than $0.01 \%$ ), neon (less than or around $0.00025 \%$ ), hydrogen-deuterium-oxygen mixture (HDO, less than or around $0.000085 \%$ ), krypton (around $0.0003 \%$ ) and xenon (around 0.000008\%). [12-14]

Specific light brown to orange-reddish coloration of Martian atmosphere is the consequence of surface dust, which is lifted and then mixed with atmosphere. Those values reach 1.5 micrometres (source: Mars Exploration Rover data). Ways of determining precise properties of Martian atmosphere are constantly perfecting [9].

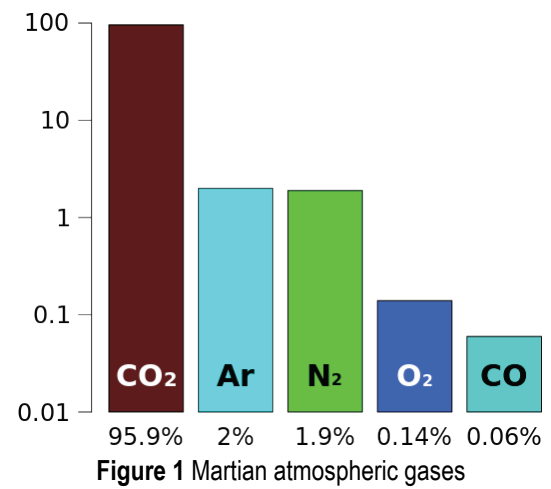

Gravitational force on Mars is around threefold weaker than the one on Earth, and it is assumed to be between 3.711 and $3.716 \mathrm{~m} / \mathrm{s}^{2}$. Since on Earth we assume this value to vary between 9.78 and $9.80655 \mathrm{~m} / \mathrm{s}^{2}$, we can apply this relation: $g_{\mathrm{M}} / g_{\mathrm{E}}=0.378-0.383$.

Comparison between atmospheres of Earth and Mars is applied to other properties as well (Fig. 2).

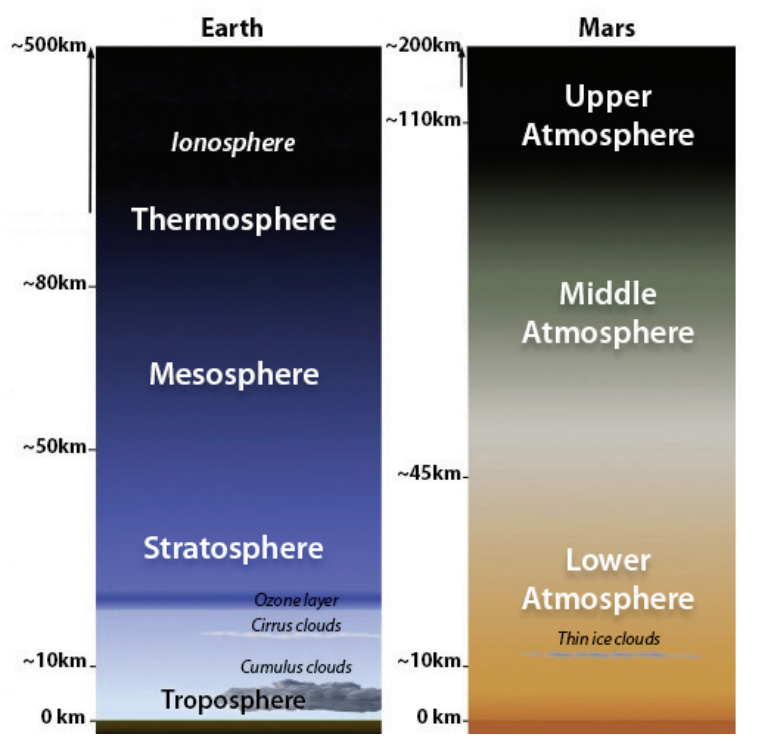

Figure 2 Earth-Mars atmosphere layers comparison

For aerodynamic analysis, it is important to establish relation between most important dimensionless aerodynamic parameters, namely Reynolds and Mach number. Their scaling (Mars-Earth), can be represented as: $R e_{\mathrm{M}} / \operatorname{Re}_{\mathrm{E}}=0.02 ; M_{\mathrm{M}} / M_{\mathrm{E}}=1.27$.

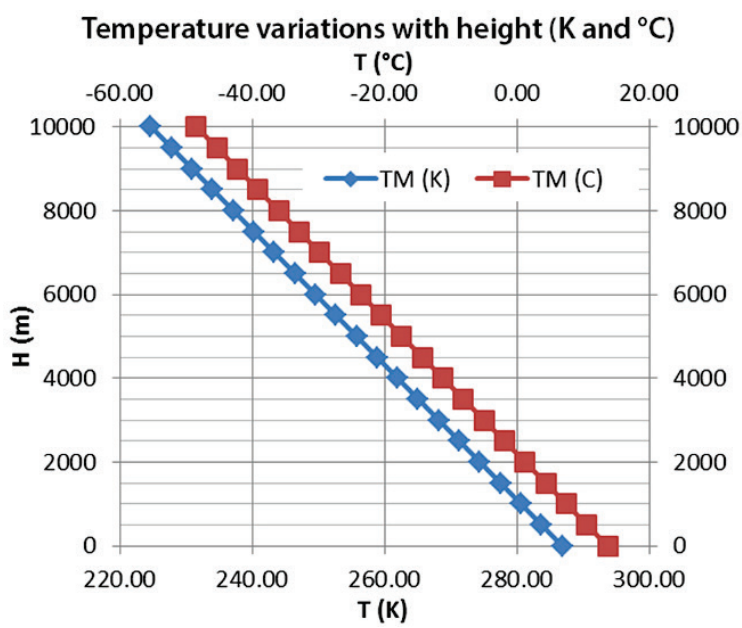

Figure 3 Temperature variations within Martian atmosphere $\left(\mathrm{K}\right.$ and $\left.{ }^{\circ} \mathrm{C}\right)$

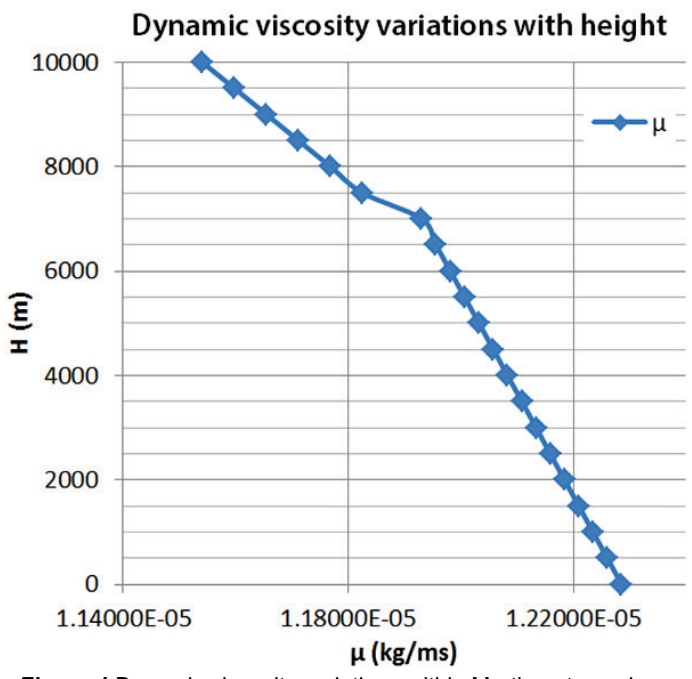

Figure 4 Dynamic viscosity variations within Martian atmosphere

Martian atmosphere allows only for generally lower Reynolds number ranges. That causes difficulties in generating sustainable lift and favourable drag. Temperature and viscosity differences in Martian atmosphere represent another challenge (Fig. 3 and Fig. 4).

\section{COMPARABLE CONCEPTS}

ALPEMA is generally comparable with specific set of concepts (Tab. 2): 1) Conceptual aircraft - Mars Sample Aircraft (MSA); 2) Conceptual aircraft - Mars Airplane (JAXA); 3) Conceptual aircraft - Mars Airplane (Fujita, Tohoku University, Japan); 4) Conceptual aircraft - ARES Mars Scout Mission (NASA).

\begin{tabular}{|c|c|c|c|c|c|}
\hline & MSA & JAXA & Fujita & ARES & ALPEMA \\
\hline Mass (kg) & 4.24 & 3.50 & 7.80 & 175.00 & 6.00 \\
\hline Wing area $\left(\mathrm{m}^{2}\right)$ & 1.150 & 1.200 & 1.200 & 7.000 & 1.150 \\
\hline Wing span (m) & 2.424 & 2.592 & 3.600 & 6.250 & 2.424 \\
\hline Wing aspect ratio & 5.11 & 5.60 & 7.50 & 5.58 & 5.11 \\
\hline Nominal ceiling & 1000 & 1500 & 3000 & 1500 & 1000 \\
\hline Cruising speed & 68 & 50 & 73 & 140 & 70 \\
\hline
\end{tabular}


Conceptual aircraft ALPEMA also has maximum Liftto-Drag ratio of 13.36; lift coefficient for maximum Liftto-Drag ratio of 0.535 ; zero lift drag coefficient of 0.02 ; maximum lift coefficient of 1.00; fuselage length of 1.2 [m]; fuselage diameter of $0.06 \mathrm{~m}$; NACA 4415 airfoil, AXI $4130 / 16$ GOLD engine and available power in two regimes of 150 and $180 \mathrm{~W}$ (Fig. 5, Fig. 6 and Fig. 7).

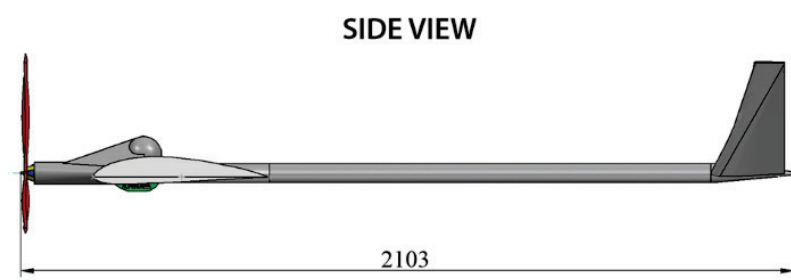

FRONT VIEW

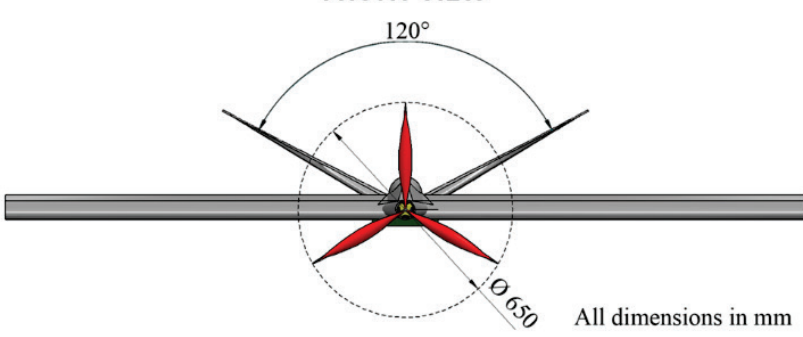

Figure 5 ALPEMA aircraft geometry

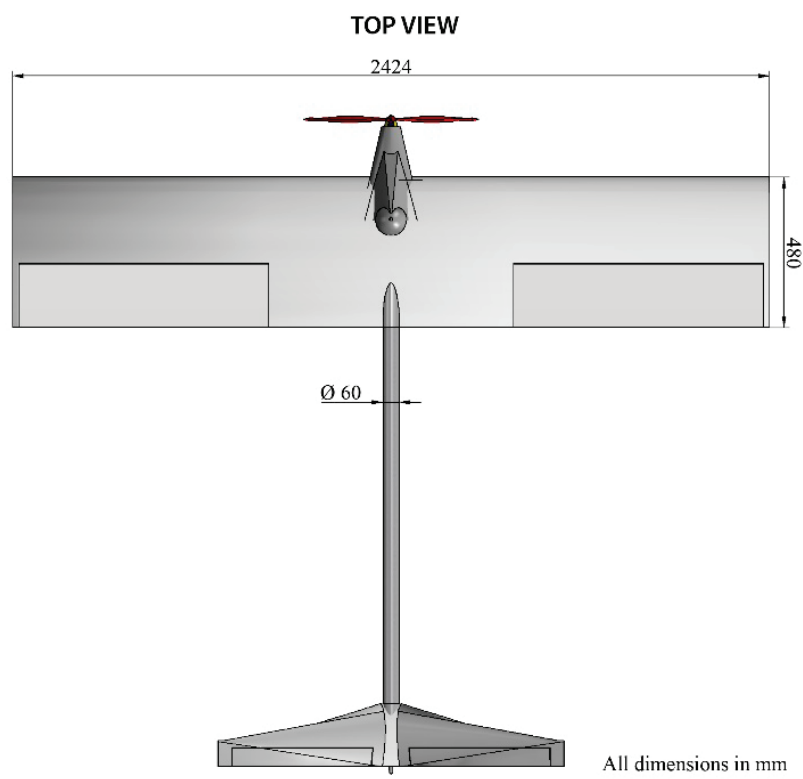

Figure 6 ALPEMA aircraft geometry

Most similarities are found between ALPEMA and Mars Sample Aircraft design (MSA) (Fig. 8) [15-17]. Apart from optimum flight ceiling and cruising speed, MSA applies aeroshell inserting into Martian atmosphere, and range of $257 \mathrm{~km}$, obtained in 63 minutes of flight. Power parameters indicate $P_{\text {req }}=89 \mathrm{~W}$ and $P_{\mathrm{av}}=128 \mathrm{~W}$, comparable with ALPEMA powerplant (AXI 4130/16 GOLD) capabilities.

Mars Airplane (JAXA) also employs aeroshell inserting, with optimum ceiling of 1500 meters [17-19]. Mars Airplane (JAXA) has usable mass of $3.5 \mathrm{~kg}$, and 300 $\mathrm{km}$ of range, obtained during 100 minutes of flight (Fig. 9).

Koji Fujita's Mars (conceptual) aircraft, developed at Tohoku University, Japan [18-21] has usable mass of 7.8 $\mathrm{kg}$, and range of $54 \mathrm{~km}$, obtained in short 12 minutes (Fig. 10).

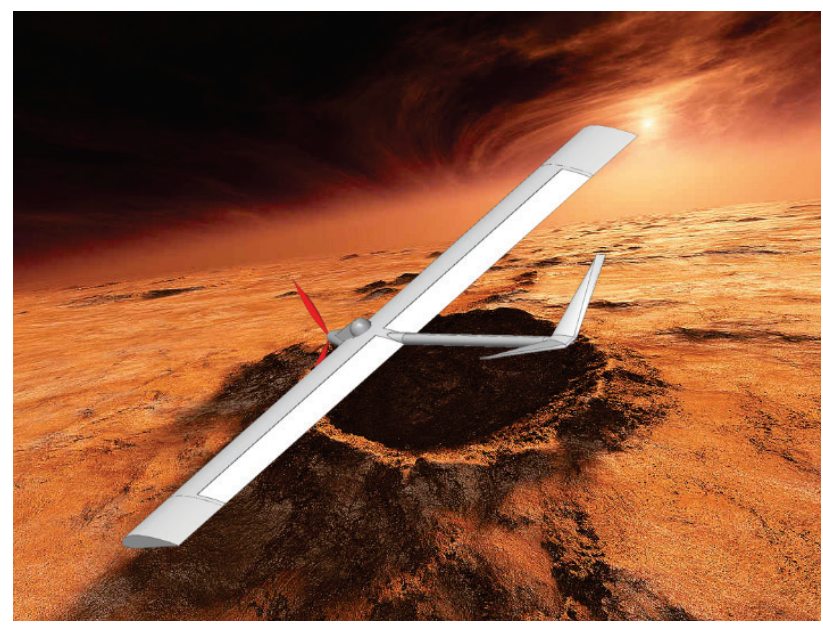

Figure 7 ALPEMA in flight (rendered image)

NASA's aircraft ARES aircraft has a different approach [22-24], which can be illustrated in significantly larger mass $(175 \mathrm{~kg}$, out of which $48 \mathrm{~kg}$ go on bipropellant fuel), and more developed and larger geometry, suitable for an aircraft powered by rocket engine. Thus is its range comparably larger $(500 \mathrm{~km})$, and it is obtained during 60 minutes of cruising (Fig. 11).

\section{PROPELLER AND EFFECTS ON ALPEMA AIRCRAFT}

Power plant characteristics direct to following threeblade propeller values: $n=4500 \mathrm{rpm} ; D=0.65 \mathrm{~m}$ (threeblade propeller diameter); $\omega=2 \cdot \pi \cdot n=471.239 \mathrm{rad} / \mathrm{s}$.

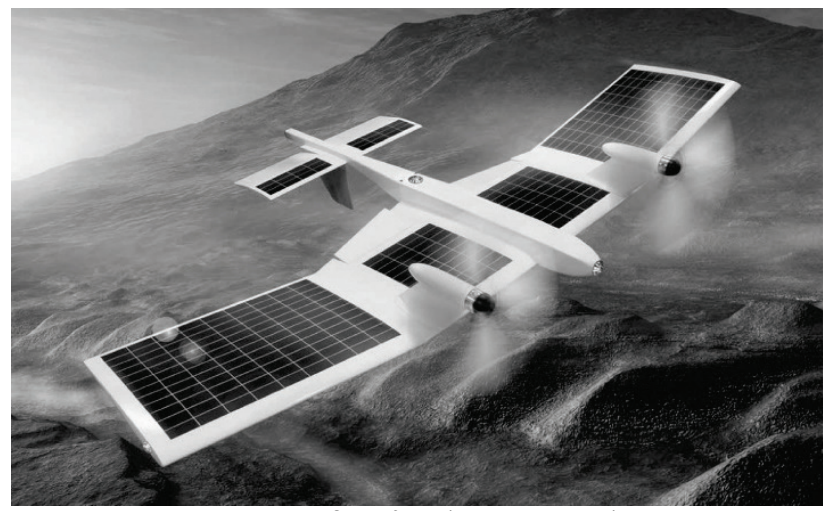

Figure $8 \mathrm{MSA}$ in flight (rendered image)

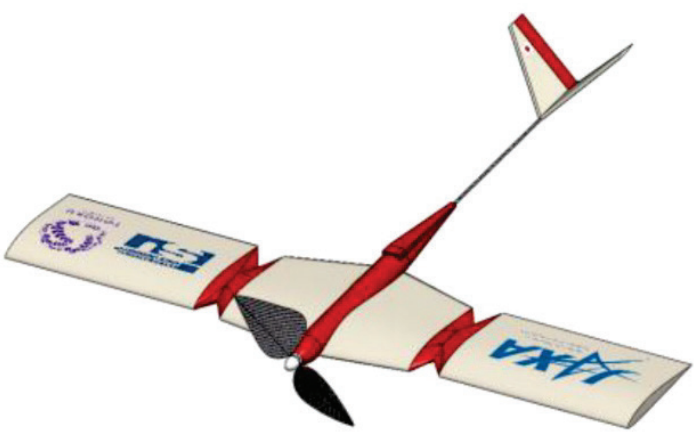

Figure 9 JAXA aircraft in flight (rendered image)

Propeller is chosen according to low power/low speed criteria, with variable pitch/step. Such a propeller uses 
relatively powerful powerplant for an efficient, safe and non-disturbed aircraft flight, with maximum thrust obtained. Mach number has to be kept in limits not exceeding 0.9 .

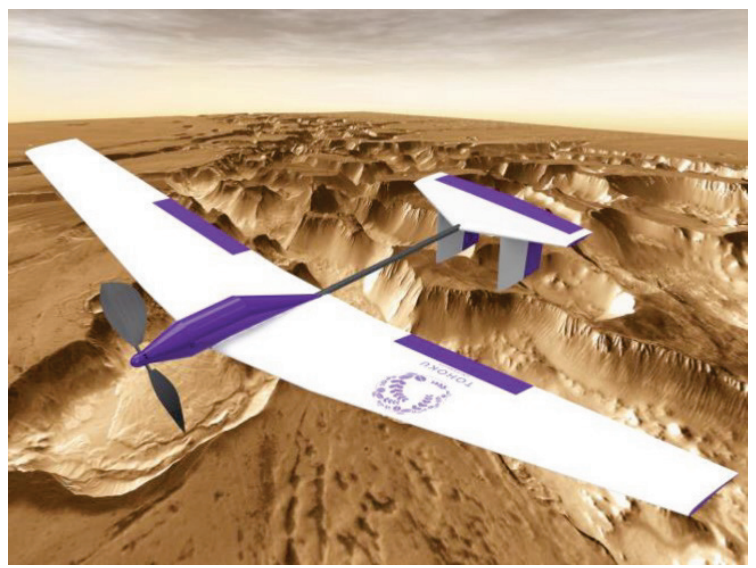

Figure 10 Fujita/Tohoku aircraft in flight (rendered image)

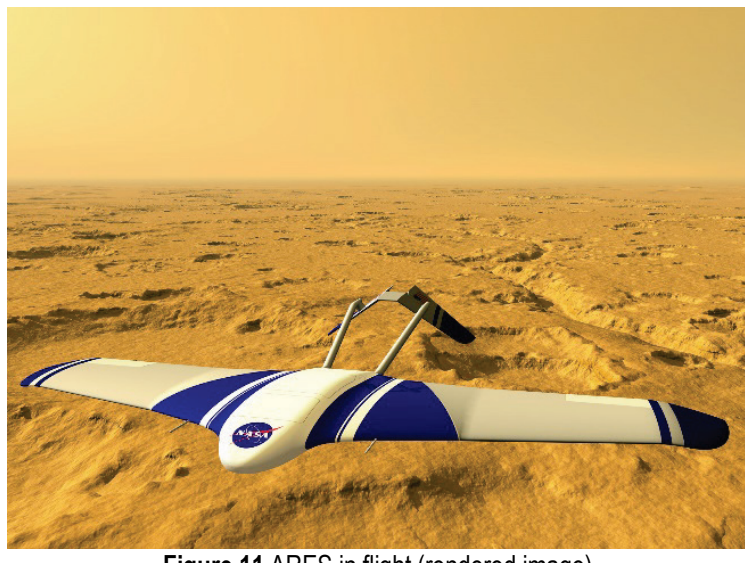

Figure 11 ARES in flight (rendered image)

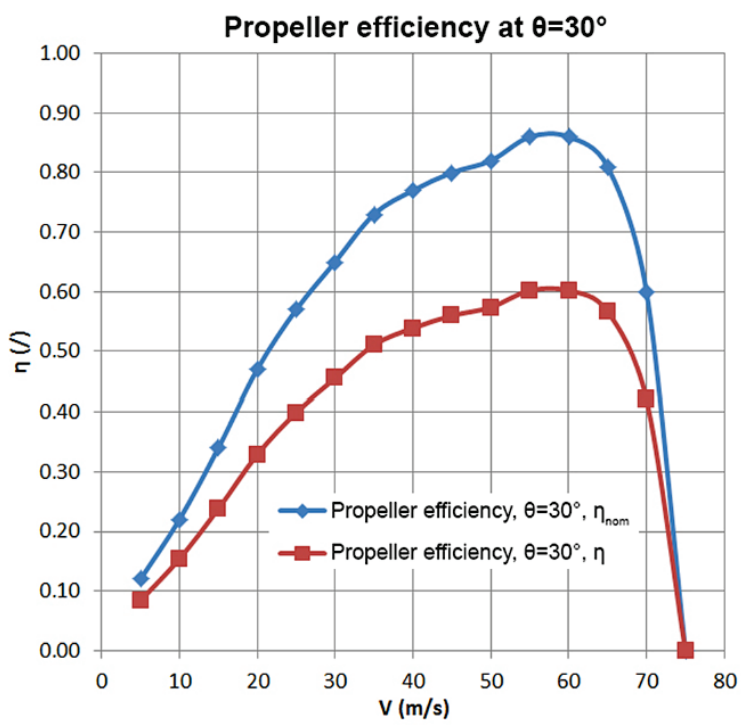

Figure 12 ALPEMA propeller efficiency, $\theta=30^{\circ}$

For three standard nominal constructive blade/ propeller angles (in position $0.75 R, R$ is length of blade [25]), $\theta$, assuming values of 30,35 and 40 degrees, it is possible to read propeller efficiency values, $\eta$. Since such values correspond to Earth atmosphere, they are reduced by $30 \%$ to correspond better to Martian conditions, together with small calculation error corrections. In this sense, propeller efficiency on Earth is marked with $\eta_{\text {nom, }}$ and the corrected one for Mars, with $\eta$ (Fig. 12, Fig. 13, Fig. 14 and Fig. 15).

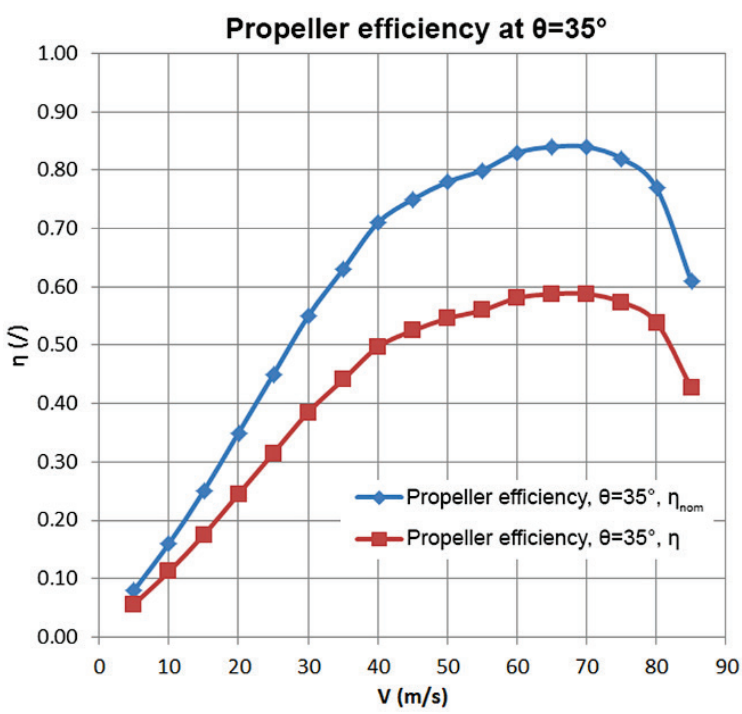

Figure 13 ALPEMA propeller efficiency, $\theta=35^{\circ}$

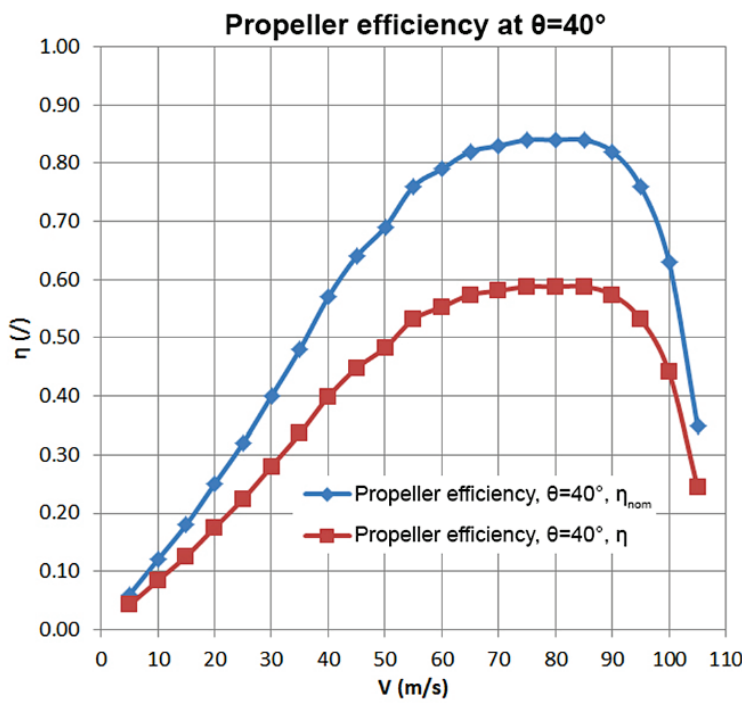

Figure 14 ALPEMA propeller efficiency, $\theta=40^{\circ}$

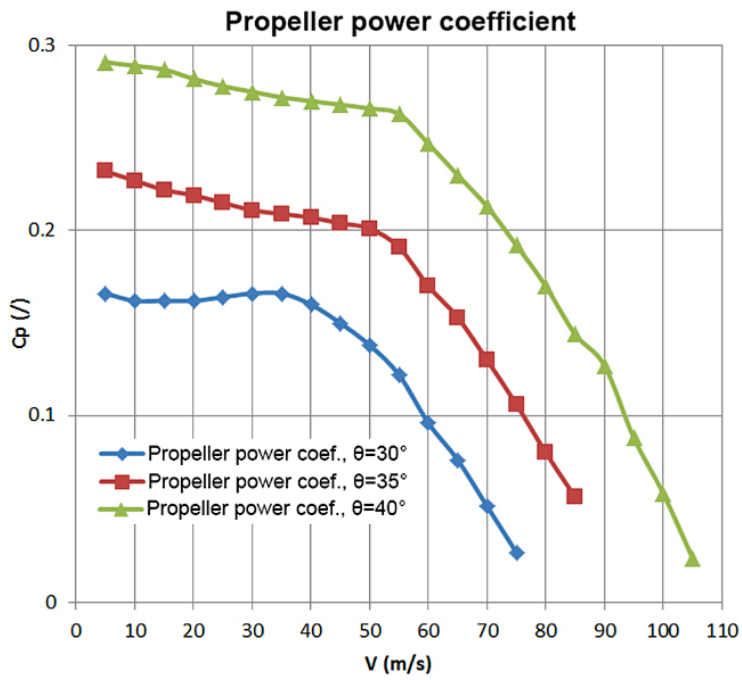

Figure 15 ALPEMA propeller power coefficient 


\section{$4 \quad$ RESULTS AND DISCUSSIONS}

Important entry parameters for analysis of ALPEMA aircraft were its drag polar and all relevant geometries and mass (Tab. 3). Knowing the powerplant (AXI 4130/16 GOLD) and its capabilities, as well as efficiency of the chosen propeller, the analysis path was focused on finding the most efficient flight envelope. To provide for that, it was necessary to determine all relevant mechanical, aerodynamic and power/energy values, namely Maximum glide ratio (i.e. Lift-to-Drag ratio, $F_{\max }$ ), lift coefficient for maximum Lift-to-Drag ratio $\left(C_{\mathrm{LFmax}}\right)$, cruising speed $\left(V_{\text {cr }}\right)$, lift coefficient for cruising speed $\left(C_{\mathrm{Lcr}}\right)$, maximum rate of climb $\left(R o C_{\mathrm{max}}\right)$, rate of climb $(R o C)$, speed for maximum Lift-to-Drag ratio $\left(V_{\text {Fmax }}\right)$, maximum lift coefficient $\left(C_{\mathrm{Lmax}}\right)$, stall speed $\left(V_{\text {stall }}\right)$, sinking speed $(w)$, power ratios $\left(P_{\text {av }} / P_{\text {req }}\right)$, minimum and maximum flight speed $\left(V_{\min }, V_{\max }\right)$, parameters of horizontal (stable) turn, as well as total drag and lift (D, L). Flight envelope is determined from the load factor $\left(n_{\max }\right)$. Powerplant regimes are observed as $P_{\text {eng }}=250 \mathrm{~W}$ and $P_{\text {eng }}$ $=500 \mathrm{~W}$.

Table 3 Drag polars of observed aircrafts

\begin{tabular}{|c|c|c|c|}
\hline Aircraft & Drag Polar & $C_{\mathrm{D} 0}(-)$ & $k(-)$ \\
\hline ALPEMA & $C_{\mathrm{D}}=0.02+0.07 \cdot C_{\mathrm{L}}^{2}$ & 0.0200 & 0.070 \\
\hline MSA & $C_{\mathrm{D}}=0.0185+0.095 \cdot C_{\mathrm{L}}{ }^{2}$ & 0.0185 & 0.095 \\
\hline JAXA & $C_{\mathrm{D}}=0.035+0.08 \cdot C_{\mathrm{L}}{ }^{2}$ & 0.0350 & 0.080 \\
\hline Fujita* & $C_{\mathrm{D}}=0.015+0.06 \cdot C_{\mathrm{L}}{ }^{2}$ & 0.0150 & 0.060 \\
\hline ARES* & $C_{\mathrm{D}}=0.02+0.06 \cdot C_{\mathrm{L}}{ }^{2}$ & 0.0200 & 0.060 \\
\hline
\end{tabular}

* First approximation, according to available data

One of the most relevant results considers changes of $V_{\min }$ and $V_{\max }$, in relation with propeller pitch angle changes, as well as altitude differences during flight (Tab. 4). These values correspond to different possible flight regimes.

Table 4 Minimum and maximum speed, according to $\theta$ values, at 1000-1500$3000 \mathrm{~m}$

\begin{tabular}{|c|c|c|c|c|c|c|}
\hline & \multicolumn{2}{|c|}{$1000 \mathrm{~m}$} & \multicolumn{2}{c|}{$1500 \mathrm{~m}$} & \multicolumn{2}{c|}{$3000 \mathrm{~m}$} \\
\hline$\theta\left(^{\circ}\right)$ & $V_{\min }(\mathrm{m} / \mathrm{s})$ & $V_{\max }(\mathrm{m} / \mathrm{s})$ & $V_{\min }(\mathrm{m} / \mathrm{s})$ & $V_{\max }(\mathrm{m} / \mathrm{s})$ & $V_{\min }(\mathrm{m} / \mathrm{s})$ & $V_{\max }(\mathrm{m} / \mathrm{s})$ \\
\hline 30 & 35.8 & 68.7 & 37.0 & 68.0 & 40.5 & 68.0 \\
\hline 35 & 38.8 & 79.7 & 40.5 & 80.0 & 43.0 & 80.0 \\
\hline 40 & 44.8 & 84.4 & 46.2 & 85.0 & 49.0 & 86.5 \\
\hline
\end{tabular}

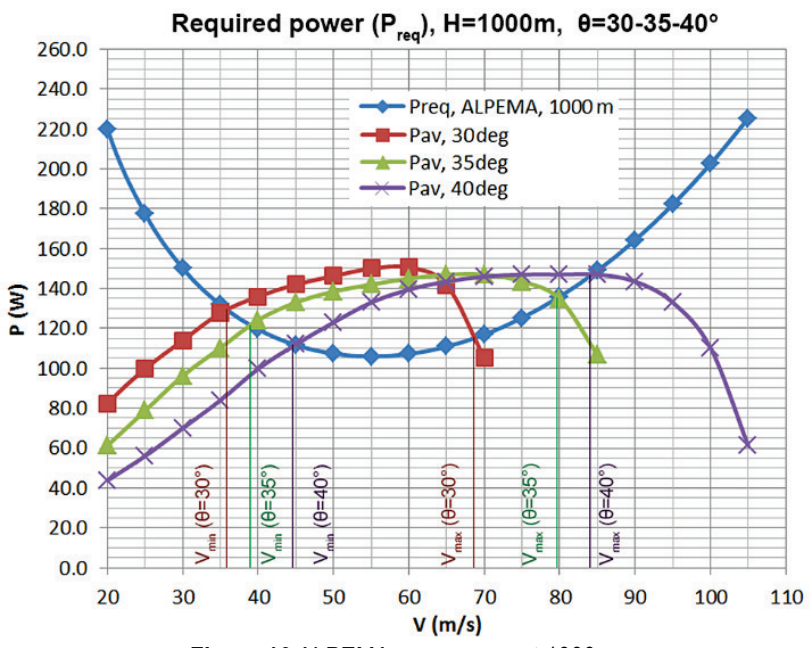

Figure 16 ALPEMA $P_{\text {req }}$ vs $P_{\text {av }}$, at $1000 \mathrm{~m}$
All those variations are best observable when $P_{\text {req }}$ and $P_{\text {av }}$ are plotted (Fig. 16, Fig. 17 and Fig. 18) in such a way that all three variations of propeller pitch angle, as well as altitude differences are taken into account.

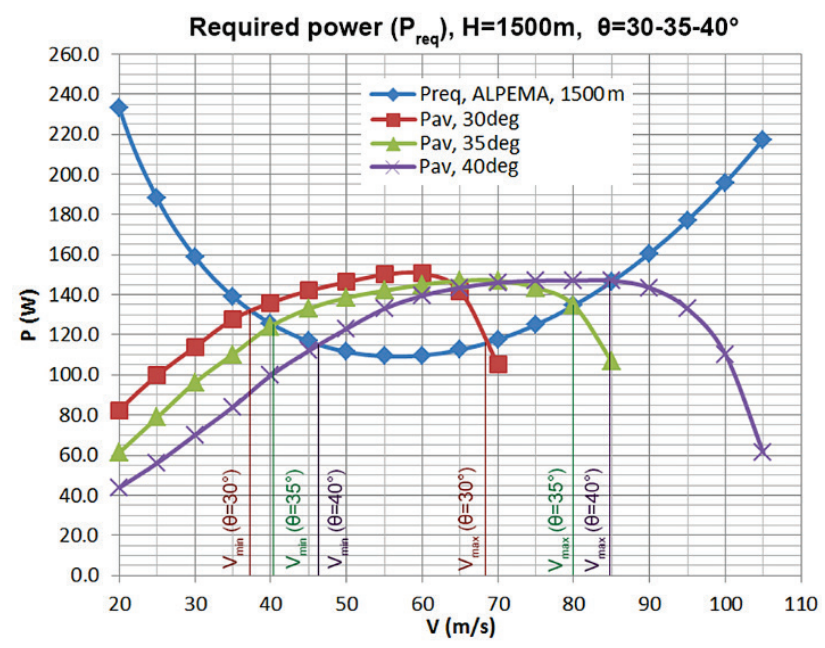

Figure 17 ALPEMA $P_{\text {req }}$ vs $P_{\text {av }}$, at $1500 \mathrm{~m}$

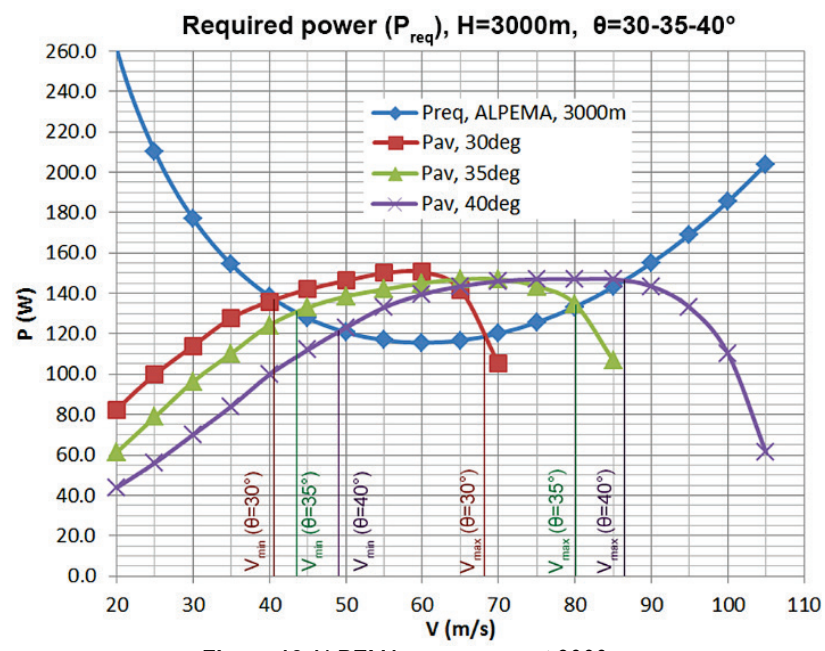

Figure 18 ALPEMA $P_{\text {req }}$ vs $P_{\mathrm{av}}$, at $3000 \mathrm{~m}$

Assuming stable engine power input, flight endurance and range can be shown to be favourable and affordable, with average speed during assumed cruising, in realistic ranges (Tab. 5).

Table 5 Endurance and range at 1000-1500-3000 m

\begin{tabular}{|c|c|c|c|c|}
\hline \multicolumn{5}{|c|}{ ALPEMA, $H=1000 \mathrm{~m}$} \\
\hline$\eta_{\text {prop }}$ & $E(\mathrm{~h})$ & $R(\mathrm{~km})$ & $V_{\text {Rmax }}$ & $P_{\text {eng }}(\mathrm{W})$ \\
\hline 0.85 & 2.01 & 460 & 64.544 & 250 \\
\hline 0.60 & 1.42 & 324 & 63.544 & 250 \\
\hline \multicolumn{5}{|c|}{ ALPEMA, $H=1500 \mathrm{~m}$} \\
\hline$\eta_{\text {prop }}$ & $E(\mathrm{~h})$ & $R(\mathrm{~km})$ & $V_{\text {Rmax }}$ & $P(\mathrm{~W})$ \\
\hline 0.85 & 1.95 & 460 & 65.470 & 250 \\
\hline 0.60 & 1.38 & 324 & 65.470 & 250 \\
\hline \multicolumn{5}{|c|}{ ALPEMA, $H=3000 \mathrm{~m}$} \\
\hline$\eta_{\text {prop }}$ & $E(\mathrm{~h})$ & $R(\mathrm{~km})$ & $V_{\text {Rmax }}$ & $P(\mathrm{~W})$ \\
\hline 0.85 & 1.84 & 460 & 69.308 & 250 \\
\hline 0.60 & 1.30 & 324 & 63.308 & 250 \\
\hline
\end{tabular}

With cruising speed established, in comparison with similar projects, load factors for ALPEMA can be determined, and prove to be optimal for such a light aircraft, not foreseen for strong manoeuvres or too heavy dynamic stresses during the mission (Tab. 6). 


Table 6 Cruising speed and load factor
\begin{tabular}{|c|c|c|c|c|}
\hline & $H(\mathrm{~m})$ & $\rho_{\mathrm{M}}$ & $V(\mathrm{~m} / \mathrm{s})$ & $n(-)$ \\
\hline ALPEMA & 1000 & 0.0138 & 70 & 1.75 \\
\hline ALPEMA & 1000 & 0.0138 & 68 & 1.65 \\
\hline ALPEMA & 1500 & 0.0130 & 50 & 0.84 \\
\hline ALPEMA & 1500 & 0.0130 & 70 & 1.64 \\
\hline ALPEMA & 1500 & 0.0130 & 140 & 6.58 \\
\hline ALPEMA & 3000 & 0.0116 & 73 & 1.60 \\
\hline ALPEMA & 3000 & 0.0116 & 70 & 1.47 \\
\hline MSA & 1000 & 0.0138 & 68 & 2.33 \\
\hline JAXA & 1500 & 0.0130 & 50 & 1.20 \\
\hline Fujita & 3000 & 0.0116 & 73 & 1.85 \\
\hline ARES & 1500 & 0.0130 & 140 & 1.37 \\
\hline
\end{tabular}

With load factors determined, and with previous data available, it is easy to plot flight envelopes, and to observe enough flexibility in sense of flight speed, to obtain various missions, and to fulfil large number of scenarios in Martian atmosphere (Fig. 19 and Fig. 20).

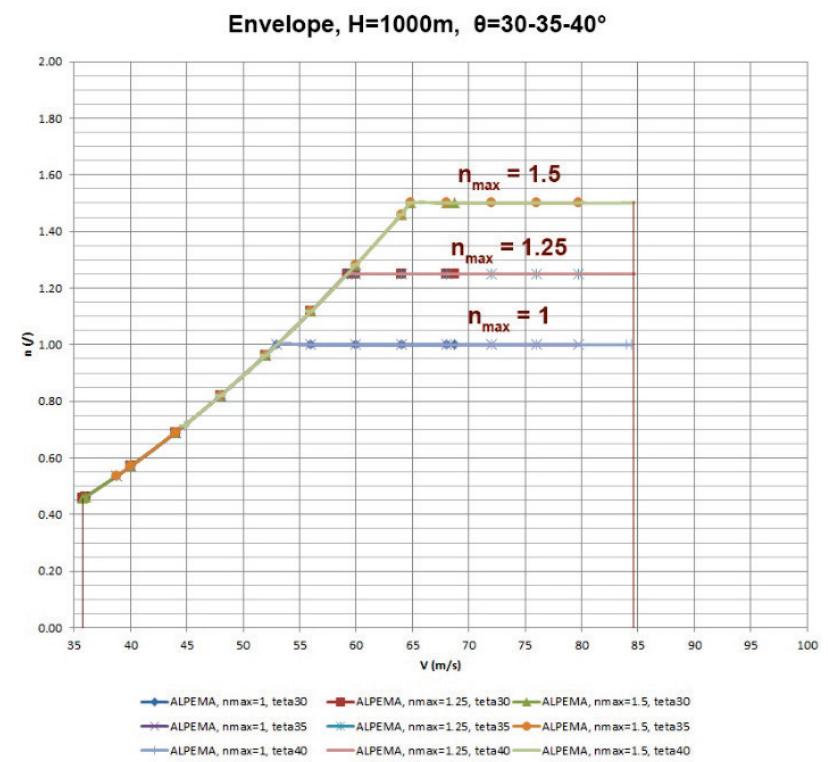

Figure 19 ALPEMA envelope, $P_{\text {eng }}=250 \mathrm{~W}, \theta=30-35-40^{\circ}$

Envelope, $\mathrm{H}=1000 \mathrm{~m}, \theta=30-35-40^{\circ} ; \mathrm{P}_{\text {eng }}=500 \mathrm{~W}$

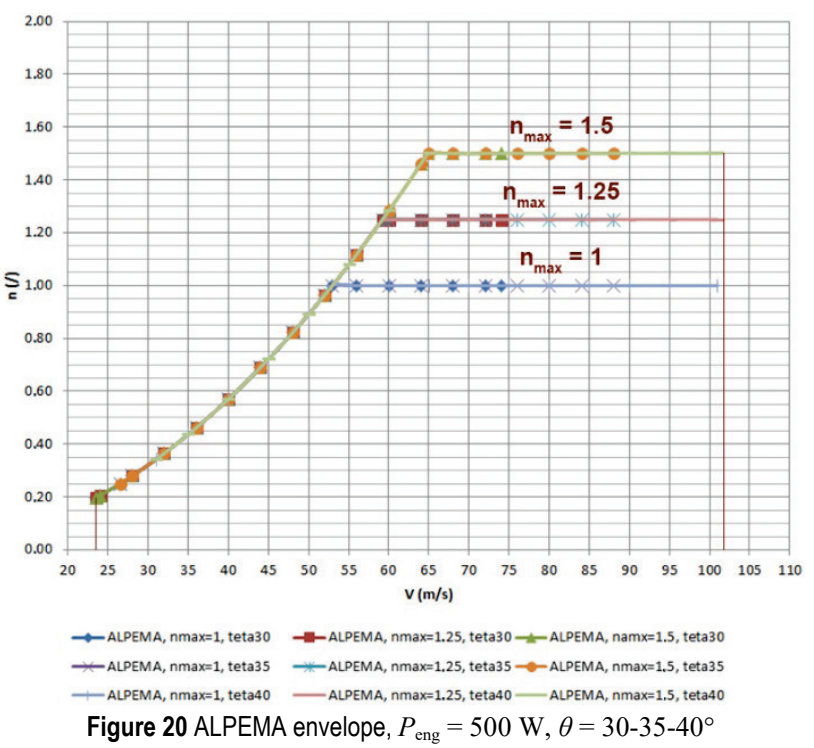

All results can be summed-up and presented together with other similar projects (Tab. 7).
Table 7 Analysis results

\begin{tabular}{|c|c|c|c|c|c|}
\hline & MSA & JAXA & Fujita & ARES & ALPEMA \\
\hline Drag coefficient [/] & 0.0330 & 0.0713 & 0.0328 & 0.0556 & 0.0410 \\
\hline Drag force [N] & 1.20 & 1.39 & 1.75 & 49.57 & 1.61 \\
\hline Maximum L/D ratio [] & 11.90 & 9.38 & 16.90 & 14.43 & 13.36 \\
\hline $\mathrm{C}_{\mathrm{L}}$ for max. L/D ratio [] & 0.441 & 0.661 & 0.507 & 0.577 & 0.535 \\
\hline Lift coefficient (cruise) [/] & 0.42 & 0.67 & 0.54 & 0.73 & 0.61 \\
\hline RoC [m/s] & 2.48 & 6.00 & 3.40 & 3.00 & 1.61 \\
\hline $\mathrm{V}_{\text {Fmax }}[\mathrm{m} / \mathrm{s}]$ & 47.6 & 35.1 & 53.4 & 111.2 & 51.2 \\
\hline $\mathrm{V}_{\text {stall }}[\mathrm{m} / \mathrm{s}]$ & 44.7 & 45.2 & 53.7 & 116.0 & 53.0 \\
\hline $\mathrm{w}[\mathrm{m} / \mathrm{s}]$ & 4.949 & 4.612 & 4.001 & 9.558 & 4.757 \\
\hline $\mathrm{V}_{\min }[\mathrm{m} / \mathrm{s}]$ & 23.50 & 8.25 & 22.46 & $/$ & $35.8 / 38.8 / 44.8^{*}$ \\
\hline $\mathrm{V}_{\max }[\mathrm{m} / \mathrm{s}]$ & 86.05 & 88.70 & 105.70 & $/$ & $68.7 / 79.7 / 84.4^{*}$ \\
\hline$\gamma_{\max }\left[{ }^{\circ}\right]$ & 3.6 & 17.8 & 3.7 & $/$ & $2.1 / 1.7 / 1.4^{*}$ \\
\hline $\mathrm{RoC}_{\max }[\mathrm{m} / \mathrm{s}]$ & 3.20 & 11.56 & 3.80 & $/$ & $1.98 / 1.70 / 1.47^{*}$ \\
\hline $\mathrm{n}_{\max }$ & 2.33 & 1.20 & 1.85 & 1.37 & 1.75 \\
\hline
\end{tabular}

* Values calculated for propeller nominal constructive pitch angles $\theta=$ $30 \% \theta=35^{\circ} / \theta=40^{\circ}$

In comparison with other available similar projects, it is noted that with ceiling above 3000 meters, atmospheric properties become disadvantageous to the design, with lesser atmospheric pressure and density, having detrimental effect on ALPEMA lift and drag. Staying within mission boundaries and environmental constraints provides for maximized results and aircraft efficiency for given goals, geometry and powerplant.

At the same time, light construction has its strength limits, which can become critical with loads and drag experienced in flight speeds exceeding drastically the design cruising speed. Therefore, it is advantageous and highly recommended to remain within boundaries of $V_{\min }$ and $V_{\max }$.

\section{CONCLUSION}

With an effective drag polar, ALPEMA has the capability to achieve optimal Lift-to-Drag ratio, with sufficient lift and non-disturbing drag forces. Superior wing aspect ratio takes the maximum from the relatively simple, rectangular wing. Such configuration has significant lift coefficient and force reserve.

Efficient three-blade propeller, in combination with small yet mighty AXI 4130/16 GOLD powerplant, provides for safe, lasting and efficient flight autonomy, illustrated with respectable 2.83 hours, and theoretical 648 $\mathrm{km}$ of range.

Results shown in flight envelope analysis illustrate strong abilities ALPEMA has for most standard missions and available scenarios envisioned. Challenges of Martian atmosphere can be surpassed, according to analysis results, with possible improvements being available.

Initial theoretical disadvantage of rectangular wings, actually presents an option for use of advanced solar panels, as an auxiliary power source, which can only add to endurance and range, thus making ALPEMA even more competitive and versatile.

Aircraft mission can be fulfilled with maximum efficiency, either with aeroshell dropping, or by standard surface take-off. Design and mission constraints provide for comfortable margin and field of activity, allowing for full scope of aircraft mission. 


\section{REFERENCES}

[1] Liu, Y., Yang, C., \& Lu, Y. (2014). Complex Modeling and Adaptive Sliding Control Law for Mars Airplane. International Journal of Micro Air Vehicles, 6(2), 73-88 https://doi.org/10.1260/1756-8293.6.2.73

[2] Reynier, P. (2014). Survey of aerodynamics and aerothermodynamics efforts carried out in the frame of Mars exploration projects. Progress in Aerospace Sciences, 70, 1-27. https://doi.org/10.1016/j.paerosci.2014.03.004

[3] Tsuji, K. \& Sunada, S. (2011). Flutter of an Aircraft Flying on Mars. Journal of Aircraft, 48(1), 341-343. https://doi.org/10.2514/1.C031186

[4] Vassberg, J., Page, G., Foch, R., \& Jameson, A. Aerodynamic Design and Optimization of the Mars Airborne Remote Exploration Scout Aircraft. 42 $2^{\text {nd }}$ AIAA Aerospace Sciences Meeting and Exhibit, Aerospace Sciences Meetings (2004). https://doi.org/10.2514/6.2004-401

[5] Datta, A., Roget, B., Griffiths, D., Pugliese, G., Sitaraman, J., Bao, J., Liu, L., \& Gamard, O. (2003). Design of a Martian Autonomous Rotary-Wing Vehicle. Journal of Aircraft, 40, 461-472. https://doi.org/10.2514/2.3141

[6] Restrepo, C. \& Valasek, J. (2008). Structured Adaptive Model Inversion Controller for Mars Atmospheric Flight. Journal of Guidance, Control, and Dynamics, 31, 937-953. https://doi.org/10.2514/1.33085

[7] Guo, W., Zhao, Y. J., \& Capozzi, B. (2011). Optimal Unmanned Aerial Vehicle Flights for Seeability and Endurance in Winds. Journal of Aircraft, 48, 305-314. https://doi.org/10.2514/1.C031114

[8] Morelli, E. A. (2012). Flight Test Maneuvers for Efficient Aerodynamic Modeling. Journal of Aircraft, 49, 1857-1867. https://doi.org/10.2514/1.C03169

[9] Dufresne, S., Johnson, C., \& Mavris, D. N. (2008). Variable Fidelity Conceptual Design Environment for Revolutionary Unmanned Aerial Vehicles. Journal of Aircraft, 45, 14051418. https://doi.org/10.2514/1.35567

[10] Papadopoulos, P., Tauber, M. E., \& Chang, I. (1993). Heatshield erosion in a dusty Martian atmosphere. Journal of Spacecraft and Rockets, 30, 140-151. https://doi.org/10.2514/3.11522

[11] Kyriss, C. L. \& Rie, H. (1967). Theoretical investigation of entry vehicle stability in the Mars atmosphere. Journal of Spacecraft and Rockets, 4(2), 272-275. https://doi.org/10.2514/3.28847

[12] Seiff, A. (1991). Atmospheres of Earth, Mars, and Venus, as defined by entry probe experiments. Journal of Spacecraft and Rockets, 28(3), 265-275. https://doi.org/10.2514/3.26240

[13] Robbins, S. J., et al. (2006). Elemental Composition of Mars' Atmosphere. Case Western Reserve University Department of Astronomy.

[14] Seiff, A. \& Kirk, D. B. (1977). Structure of the Atmosphere of Mars in summer at mid-latitudes. Journal of Geophysical Research, 82(28), 4364-4378. https://doi.org/10.1029/JS082i028p04364

[15] Liu, T., Oyama, A., \& Fujii, K. (2013). Scaling Analysis of Propeller-Driven Aircraft for Mars Exploration. Japan Aerospace Exploration Agency. https://doi.org/10.2514/1.C032086

[16] Fujioka, N., Nonomura, T., Oyama, A., Makoto, Y., \& Fujii, K. (2014). Computational Analysis of Aerodynamic Performance of Mars Airplane. Transactions of the Japan Society for Aeronautical and Space Sciences, Aerospace Technology Japan, 12.

[17] Anyoji, M., Okamoto, M., Hidaka, H., Nonomura, T., Oyama, A., \& Fujii, K. (2014). Planetary Atmosphere Wind Tunnel Tests on Aerodynamic Characteristics of a Mars Airplane Scale Model. Transactions of the Japan Society for Aeronautical and Space Sciences, Aerospace Technology Japan, 12. https://doi.org/10.2322/tastj.12.Pk_7
[18] Fujita, K., Luong, R., Nagai, H., \& Asai, K. (2012). Conceptual Design of Mars Airplane. Transactions of the Japanese Society for Artificial Intelligence, Aerospace Technology Japan, 10, 5-10. https://doi.org/10.2322/tastj.10.Te_5

[19] Tajima, H., Sunada, S., Tokutake, H., Okamoto, M., \& Okamoto, M. (2011). Flight Stability of an Airplane on Mars. Transactions of the Japanese Society for Aeronautical and Space Sciences, 54(185/186), 205-211. https://doi.org/10.2322/tjsass.54.205

[20] Fujita, K., Nagai, H., \& Oyama, A. (2016). A Parametric Study of Mars Airplane Concept for Science Mission on Mars. Transactions of the Japanese Society for Aeronautical and Space Sciences, Aerospace Technology Japan, 14, 8388. https://doi.org/10.2322/tastj.14.Pk 83

[21] Fujita, K., et al. (2012). Conceptual Design of a Miniature, Propeller-Driven Airplane for Mars. Proceedings of the $50^{\text {th }}$ AIAA ASM, AIAA 2012-0847. https://doi.org/10.2514/6.2012-847

[22] Guynn, M. D. \& Croom, M. A. (2003). Evolution of a Mars Airplane Concept for the ARES Mars Scout Mission. $2^{\text {nd }}$ AIAA Unmanned Unlimited Systems, Technologies, and Operations - Aerospace Conference. https://doi.org/10.2514/6.2003-6578

[23] Kenney, P. S. (2003). Simulating the ARES Aircraft in the Mars Environment. $2^{\text {nd }}$ AIAA Unmanned Unlimited Systems, Technologies, and Operations - Aerospace Conference. https://doi.org/10.2514/6.2003-6579

[24] Braun, R. D., Wright, H. S., Croom, M. A., Levine, J. S., Spencer, D. A. (2006). Design of the ARES Mars Airplane and Mission Architecture. Journal of Spacecraft and Rockets, 43(5), 1026-1034. https://doi.org/10.2514/1.17956

[25] (1986). Pogonski sistemi letelica - Elise. Tehnička enciklopedija / Gajić, D., Rašuo, B. Zagreb : Jugoslavenski leksikografski zavod, X. tom, 509-515.

\section{Contact information:}

Marko Ž. EKMEDŽIĆ, MSc. Mech. Eng.

European XFEL GmbH

Detector development group

Holzkoppel 4, 22869 Hamburg, Germany

marko.ekmedzic@xfel.eu

Aleksandar BENGIN, Prof. PhD

University of Belgrade

Faculty of Mechanical Engineering

Aeronautical Department

Kraljice Marije 16, 11000 Belgrade, Serbia

abengin@mas.bg.ac.rs

Boško RAŠUO, Prof. PhD

University of Belgrade

Faculty of Mechanical Engineering

Aeronautical Department

Kraljice Marije 16, 11000 Belgrade, Serbia

brasuo@mas.bg.ac.rs 